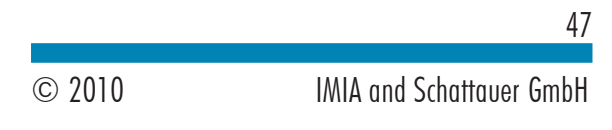

\title{
Medical Decision Support Systems in Africa
}

\author{
G. Bediang, C. O. Bagayoko, A. Geissbuhler \\ Department of Radiology and Medical Informatics, Geneva University, Switzerland
}

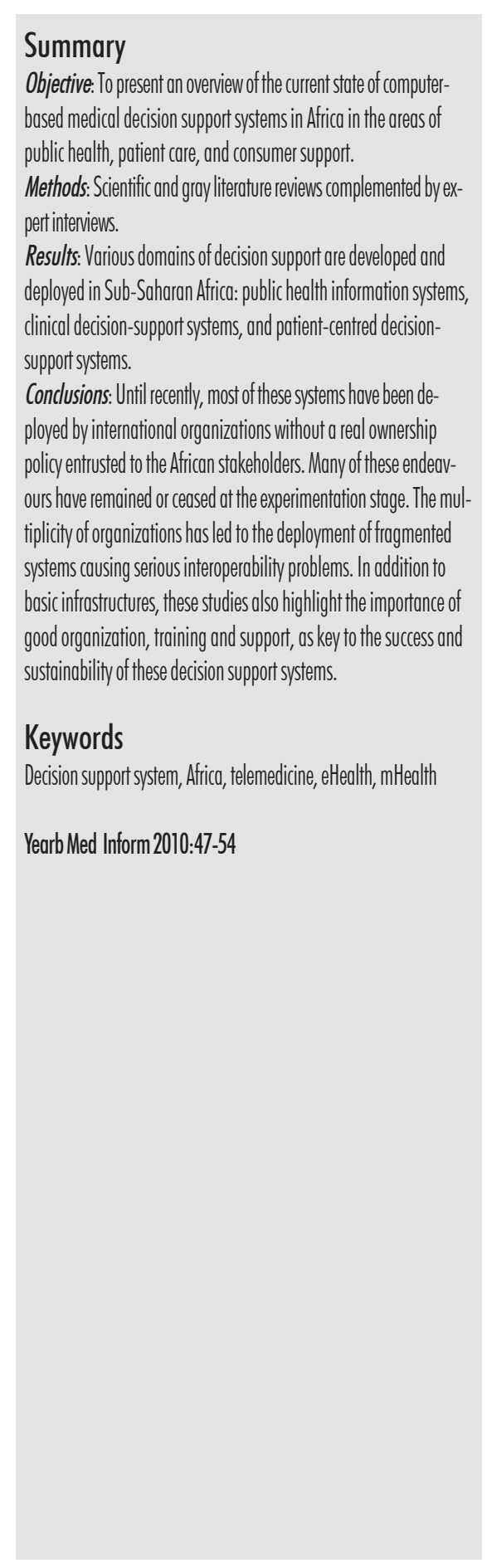

\section{Introduction}

The scope of medical decision support systems has evolved over time. Initially based on models of deductive logic (clinical algorithm), Bayesian probabilistic, heuristic, analytical models and expert systems - the "Greek Oracle" $[1,2]$ model, the first systems of decision support were mainly focused on computer-aided diagnosis in medicine. These systems were based primarily on theories of clinical reasoning. The practitioner would enter the data collected from the patient in a system and wait for it to provide the correct diagnosis [2]. Although these approaches were very innovative, they were not used widely. In order to increase their clinical usability, diagnostic decision-support systems have evolved into integrated systems in the work environment and processes [2] used by practitioners "in order to limit the amount of data that clinicians must re-enter across isolated systems" and provide timely assistance to the decision-making process based on the clinical information of patients [3]. The concept of decision-support has widened to encompass computerized patient records, general medical knowledge base information resources and applications for diagnosis, medical prescription and the interpretation of test results, as well as alerting and reminder systems [3-12].

Furthermore, the concept of supporting the clinician with patients' diagnosis and therapy has evolved into an approach that also integrates the support of managers and policy makers in their decisions for patient populations [13]. Tan [14], illustrates this change in approach, defining de- cision support in health as «an interactive, user-controlled system (usually computer-based software) that are designed specifically to facilitate the decision maker (health administrators or clinician) in using data, models, and knowledge elements to solve semistructured and complex decision ». This definition, therefore, includes the efficiency of decision making (diagnosis, treatment) in the clinical environment but also in the broader field of healthcare and health. It argues that all stakeholders in the health system (health professionals, managers, policy makers) should have the information needed to improve the management of patients, services and health system, respectively [15]. In addition, this new approach also incorporates direct support of patients by themselves [13].

In Africa the decision support is increasingly integrated into health systems, as there is a growing demand for information to help policy building, health systems planning and monitoring. The impact of health programs in order to achieve the Millennium Development Goals $[16,17]$ cannot be neglected. In addition, given the propagating crisis of health professionals (insufficient professionals, inadequate distribution, brain drain, etc...), the development of information technology and telecommunications offers new opportunities for decision support through access to remote expertise for professionals located in isolated areas [18].

The objective of this review is to present a critical overview of the current state of decision support systems in Africa in the areas of public health, patient care, and consumer decisionsupport. 


\section{Methodology}

A literature search was performed through MEDLINE and over the World Health Organization's databases: WHO headquarters library database (WHOLIS) and WHO-AFRO Library (AFROLIB, African Index Medicus). Papers describing implemented systems in Sub-Saharan Africa were reviewed. Additional information and material was obtained through interviews of experts in the field of e-health and medical informatics involved in decision-support systems implementations in Africa.

\section{Decision Support Systems for Public Health in Africa}

\section{Background and Objectives}

In the late 1980 's, prompted by international agencies and donors, pilot projects for implementing District Health Information Systems (DHIS) were launched in African countries [19]. Far from being mere tools for routine collection of data, the DHIS were designed with the objective of improving the health of populations within a health district [20]. Health districts should, therefore, be equipped with systems able to collect, analyze and interpret data in order to create locally relevant information [21]. As available, this information should be shared between different actors in the health system to be used for surveillance, monitoring, evaluation of effectiveness, the impact of interventions and health programs, planning and resource management [20-22].

Later, in the mid 1990's, after reforms of many health systems and under the leadership of national research organizations, other countries, such as South Africa, have initiated nationwide implementation of various DHIS projects [23].

\section{Design, Operation and Challenges of DHIS}

Apart from South Africa, where the process of setting up a DHIS has sprung from national interests involving stakeholders and national research organizations [23], the majority of DHIS projects in Africa have been driven by international agencies and donors [19, 20]. Under international pressure and given the time constraints for these projects, the design of DHIS was limited to central levels, and implementation would be carried out without involving all stakeholders. These aspects have been very important because the sustainability of DHIS has depended heavily on the ability of national and local authorities to maintain these activities. However, the DHIS was mainly designed for the collection of patient data, thus relegating to a secondary level the administrative data collection and management of human and material resources [19, 20].

In the health systems of most African countries, there is a multiplicity of international actors. These organizations have developed many vertical programs like tuberculosis, immunization, HIV / AIDS and the prevention of motherto-child transmission of HIV / AIDS $[24,25]$ supporting the existence of a multitude of records and various forms. Several difficulties impeding the proper functioning of DHIS and the quality of data have emerged from the studies of such systems.

The fragmentation of data from the decision support systems has often been noted upon [24, 25]. This comes from the lack of information sharing between providers of care within a health district, but also between institutions or groups of users of such information, which are: public or private health institutions, local authorities, communities and governments [24, 25]. The result has been a frequent lack of coordination, an unnecessary complexity and duplication of data collection processes and unsystematic or disorganized health policies. In addition, the fact that this vast amount of information needs to be captured by health professionals themselves has resulted in the perception of their workload having increased. Moreover, the information collected was often redundant [20, 25-27].

Another set of difficulties relates to resources allocated for the operation of DHIS. Staffing of DHIS was often inadequate. Most of them had little or no training and so lacked competent skills to ensure its optimal performance [20, 25]. The managers were not sufficiently supported in their activities when using the application. Teams also gave it less attention due to weak financial resources, insufficient equipment and infrastructure [20, 25].

The availability and accessibility of data produced by the DHIS were not guaranteed for various groups and users of this information in the district, and as result, this information has been frequently underutilized. Managers and health care professionals have not used it to inform, improve or monitor health programs in the district. Moreover, there was no analysis and use at the point of collection. There was virtually no feedback from the district health service to health centers. Even if these feedbacks were reported, there is often the problem of consistency between the information provided and the real needs of the managers [20, 25]. Other barriers to the use of the data were also identified: the constant changes in staff and poor communication of knowledge, insufficient information integration in the activities of the health district, inadequate access to data denominator in order to calculate the indicators, the need for suitable technical, administrative and political means and finally the risk of conflict of ideas or interference with political plans $[22,25]$.

\section{Information Quality}

In most studied systems, the data have been considered unreliable [20, 25, 26]. An evaluation for DHIS in Kenya has found that "information produced was 
$30 \%$ accurate, $19 \%$ complete, $26 \%$ timely, $72 \%$ relevant, the level of confidentiality and use of information at the point of collection stood at $32 \%$ and $22 \%$ respectively and information security at 48\%" [20, 25, 26]. Another study on a health information system on the mother-child transmission of HIV, showed that the completeness or accuracy of the data varied depending on the nature of the data collected [26]. In addition, the completeness of the data does not mean they are automatically correct. A study of the data to monitor an Anti-Retro Viral (ARV) treatment program in Malawi showed that, despite the fact that health facilities had complete clinical and laboratory data in their registry, only $40 \%$ of them were accurate [28]. On the other hand, it is noted that data on morbidity and mortality were often adequate $[20,25,26]$.

In these information systems, data are collected in the registry of health services and then transmitted in form of summaries to the district health authorities. This raises the problem of data consistency because there is a large discrepancy between the values of records and summaries of health facilities but the details between the monthly summaries of health facilities and reports of district match perfectly [26]. Through this observation, the suggestion is made that the problems in the integrity of the data originate in the process of data collection and analysis. Other studies find a discrepancy between data from local and national offices and point to the significant under-reporting of data as the factor [29].

\section{Computerization and Quality of Information in the DHIS}

Most of the studied information systems were only partially computerized. The computerization of the DHIS has been identified as a factor with the potential to improve the process of data collection, analysis, storage and avail- ability [21, 24]. Moreover, a satisfaction survey of DHIS software in Tanzania $[21,24]$ demonstrates the high reliability of its data, although its usability by health professionals is relatively low. However, this study has noted the difficulty of the reproduction and integration of information from the multitude of existing paper forms in the DHIS application. Another study reveals the health professionals' lack of computer skills as an adverse factor [25]. Computerization cannot really improve the functioning of a DHIS and users' satisfaction unless there is an improvement in dealing with the lack of technological infrastructure [21, 30].

Sustainability of a DHIS is improved if it is supported by a centralized, social and organizational process [21] : health professionals must understand "why" the data are collected and "how" they are used [25]; training and support must be guaranteed [21, 24] in order to provide skills, including computer literacy [25], as well as at least minimal knowledge on data analysis and interpretation [25].

The challenge for the health systems of all countries around the world is to positively optimize the management of health services (effectiveness, efficiency) [15]. Although there is a will in that direction, it is clear that most developing countries, particularly those in Africa, have yet to make considerable investments in medical information systems to improve their health care systems and their ability to make informed decisions [31]. There are many constraints and difficulties to overcome: the process for defining the basic needs for information, development of standardized data collection, promotion of health informatics and training [21], as well as the development of a culture of information among health professionals, managers and policy makers [21]. This culture of information is essential for the enhancement of information systems; it involves the recognition of the value of data by all teams in different facilities, as nec- essary for the effective management of patients, health care services performance, planning and development of health policies $[21,26]$.

Another important element is the need for an effective partnership between different actors in the establishment of an information system [20]. The various steps, which are the design, implementation and operation of a DHIS, should involve all the stakeholders (i.e. designers, donors, producers and users) [19]. This participatory approach has the advantage of ensuring shared ownership, and promotes institutionalization and sustainability.

Studies also recommend the use of simpler data collection tools, the reduction of the number of registers and the definition of a limited set of key indicators which are shared by various vertical programs $[16,32,33]$. This streamlining and simplification of the process of collecting the data is as relevant as the decision to computerize the system itself. It is therefore necessary to integrate the information from existing paper forms [24]. However, to fully assume its role as decision support tool in health, DHIS should allow the collection of other data fields such as administrative and management information (e.g., human resources, material resources, financial information). Also, the DHIS could in addition involve the collection of information on selected determinants of health such as the availability of food, water, and sanitation shelters [20].

Identified in most studies, inadequate infrastructure, equipment and financial resources are factors impacting the performance of a DHIS. Moreover, insufficiency in quantity and quality of human resources is also an important factor. Thus, several authors have recommended in their work that a specific staff be given the task of running the activities of the DHIS, not only to decrease the workload for health professionals but also to improve the quality of data collected [21, 25, 28]. Managers and health professionals should be adequately trained and adapted [21, 24, 
26]. This training must be integrated within the entire health system in the perspective of overall social development $[21,24,26]$. Even if the quality of training is essential for ameliorating practices, we must nevertheless recognize that it must be combined with other elements to generate the maximum positive effect $[21,24,26]$. Training managers and health professionals in "computer literacy" has also been found as an important instrument for the proper working of a DHIS [21, 24, 26]. They should also be supported and supervised throughout all activities related to the DHIS.

There is a renewed interest in the large-scale deployment of DHIS, in particular through the Africa Health Infoway project [34]. Its main partners are the International Telecommunication Union (ITU), the World Health Organization, the African Union and other interested local, national and global entities. Established for five years (2008-2013), this project aims to develop and implement solutions based on information technology to refine decision-making mechanism in the health districts of all African countries.

\section{Evaluation of DHIS}

Many criteria have been identified and deemed important to evaluate a DHIS and thus, increase its sustainability [21, 23]. They should be taken into account and be part of the process from its design to operation $[19,21]$. First, in the design phase, a system analysis to guarantee the viability of DHIS before committing any resource for its development or deployment should be undertaken. Second, during the implementation, the evaluation would consist of monitoring the main criteria set in the flowchart of the application in order to pinpoint the errors and apply adequate alterations. Finally, in the operation phase, it verifies the effectiveness and impact of the DHIS in the health system.

\section{Clinical Decision Support Systems}

\section{Electronic Medical Records Systems (EMR Systems)}

In Africa, many countries are devoting much effort to set up EMR systems. The implementation of EMR systems has been encouraged by the growing need of governments, donors, professionals and researchers to have reliable clinical data on the health care needs of populations correlated to insufficient resources [35].

Thus, in 2001, with the participation of many international partners, the first experience of an African EMR system was conducted in a rural health clinic in Kenya [36, 37]. Given the success of that project and the importance and attention given to HIV/AIDS, that EMR systems has subsequently been modified to support specific treatment of patients with HIV [38, 39]. Consequently, several EMR systems projects were then being carried out in many other African nations [40-42], mainly in the field of HIV and associated diseases such as tuberculosis. Of all these ventures, OpenMRS is currently the most published system throughout the continent.

\section{OpenMRS}

In Africa, the first implementations of EMR have been made with the web based EMR created by PIH (Partners In Health) for general care in primary health care system $[36,37]$ or with MSAccess system for specific programs such as AMPATH [39]. OpenMRS is an EMR system for developing countries with limited resources $[35,43]$. It was designed as a flexible replacement for these systems. It is based on MySQL, Java and the Tomcat application server. Its evolution has been marked by its specific guidance on the care of patients with HIV and TB, and its increasing ability to manage a growing number of observations of patients [43]. Its devel- opment and implementation on a large scale in Africa have been possible through the collaboration of many national and international partners [43]. Currently, OpenMRS is based primarily on open source components. It uses international standards and its data model is based on a semantic dictionary specifically tailored for low-resource settings [35, 43, 44]. Most of the data are structured and reported on paper forms by health professionals. They are then collected to be entered in the computer system [35, 43, 44].

OpenMRS has been designed to allow local health professionals monitor continuously the care provided to patients and adapt evolving strategies of care as needed [38]. This view assumes that the information generated must be returned to the care providers who are its original sources thus providing "clinical utility" [43]. This helps verifying that the collected information is reliable and of good quality [43]. Thus, for example, for HIV patients enrolled in the OpenMRS program we can have an accurate fact about their number and distribution, the results of laboratory tests made by them (i.e. CD4) and those who have started ARV treatment or who require additional one. From these data, the system is capable of generating information and reports useful for practitioners to help improve their performance in the care of patients [38]. It becomes easy to identify new infections or side effects of medications. Professionals no longer have to worry about the availability of data on patients [45]. Studies show that the provision of information in an EMR system to the health professionals has the ability to improve the quality of care [46], reduce medical errors [47, 48] and unnecessary tests [49]. Patients who missed their appointments can also be identified. With the aid of computerized reminders $[50,51]$ and alerts, OpenMRS has allowed mobile teams, not only to identify affected patients but also the reasons for the failure to administer appropriate solutions and provide care for these patients either at their homes or work places [38]. 
This method has significantly improved patient adherence to treatment with ARVs. It has also made possible to create links between HIV patients and their community system, and have a more comprehensive care.

Moreover, additional modules help to manage, for example, the stocks of ARV drugs in pharmacies, or the substitution feeding of pediatric patients [38].

Another important aspect was the integration of a search algorithm based on numerous parameters (name, ID number, diagnosis) into OpenMRS with a low failure rate for tracking patients registered in the system [43]. This feature has been enhanced by the normalization of captured data through a dictionary of concepts [43, 44]. It makes the queries about patients easy, fast, and adequate, thus improving the efficiency of the workflow of care providers [45].

The continuity of the recorded patient data, their availability and accessibility by multiple users are also contributing to improve the performance of health professionals [45].

However, this information should also be available for other stakeholders of the health care system such as managers, researchers and donors [45]. Through regular reports such information can be very helpful in planning and coordinating resources such as laboratory exams, medications, human resources, infrastructure, and even logistics [38].

The implementation and deployment of OpenMRS in Africa have seen a lot of positive returns. These successes are due to the involvement and collaboration of many national and international institutional partners [35]. Such cooperation has been fostered by the World Health Organization [43]. Amongst the challenges encountered, the first one has been to ensure effective working relations and coordination between all the institutional partners and development teams involved in the process. Besides regular coordination meetings, developing a network of implementers has been the engine of success [52]. Such team consists of "health information systems professional that fo- cuses on installing and configuring software and systems to meet the needs of a particular health system information requirement with little or no programming of the actual software." This network's aim has been to develop a genuine community among developers and implementers through the different existing channels of communication and exchange like annual meetings, internship programs and a website. The OpenMRS implementers' network also had the opportunity to discuss and share their experience with their peers. The network has supported South Africans in their experimentation [52], thereby, reducing the perceived barriers to the implementation of EMR systems in developing countries [48, 53].

Another obstacle was to ensure the system's evolution. The data model had to be changed several times and the transaction function was also rebuilt and adjusted so the OpenMRS could support the growing number of patients and observations $[48,53]$. Then, some mechanisms were put in place to safeguard the reliability of coded data, security, confidentiality and data synchronization because most of these data had been provided by remote sites as paper forms [38, 43].

In terms of flexibility, besides HIV and TB care, the code and infrastructure of OpenMRS should allow modifications to support other types of care [43].

Although OpenMRS is an open source project, its implementation, management, expertise and the infrastructure required for its adaptation and operation represent a significant burden. For the sustainability of such programs, it is therefore, important to have an even broader participation of all the partners of the health care system (i.e. private or public, national or international).

\section{Telemedicine for Decision Support in Africa}

Unlike the EMR system, the decision support in telemedicine is based on the use of a system to access remote expertise. This is used to support professionals located in rural or isolated areas [18, 54]. In this context, the iPath platform is one that has been most successfully used in Africa.

Developed at the University of Basel and accessible via the internet, iPath was initially designed to support diagnosis in pathology, and has been expanded to other domains such as dermatology and general medicine [55]. Different users (experts and non-experts) meet in focus groups based on their network affiliation or their interests. Non-experts can submit cases via the web (text, images) and ask specific questions for experts. Experts provide advice and answers to questions asked by non-experts, and this in a clinically useful time frame. The discussions can synchronous or asynchronous [55].

This platform is used by the Telemedicine Network in French Speaking Africa known as RAFT (Réseau en Afrique Francophone pour la Télémédecine) for asynchronous teleconsultations from isolated care professionals [18]. In order to deal with connectivity problems and with the enormous workload of specialists, medical coordinators mediate the tele-expertise requests, in order to identify and bring qualified professionals to discuss and address the specific inquired clinical cases, thus improving response rate and response time [18].

Since 2002, iPath is also used as an application in a teledermatology project in rural South Africa, the Port St. Johns project [54. 56, 57], and in the West African Doctors and Healthcare Professionals Network [56].

Using a different platform known as telederm.org [58], "The Africa Teledermatology Project", initially started in Uganda and currently covering countries of Southern and Eastern Africa, is being expanded since 2007 [56]. Its objective is to support African health professionals in the management of patients with skin diseases, especially those related to HIV/AIDS. It provides assistance with remote diagnosis, edu- 
cational resources and support for research projects.

\section{mHealth for Decision Support in Africa}

With the development of mobile technologies (smartphones, GPRS, 3G, and WiMAX), mobile eHealth tools (mHealth) are being developed to support healthcare professionals in Africa [59]. In South Africa, with the project called Cell-Life project [59] where the focus is on HIV patients, health workers have real-time access, through mobile devices, to data recorded during their clinical or hospital visits. The information collected on the patients' condition is transmitted to a remote database managed by the caregiver. It gets analyzed by the manager and the health worker receives feedback and the type of attitude to pursue, over the phone.

Another model was tested in remote areas of Kenya in 2002, using satellite phones and Personal Digital Assistants (PDA) to capture data about patients during the consultation and access clinical and prescription databases. When needed, expertise is sought from specialized centers in the USA. The evaluation of this system has confirmed its usefulness in the rapid access to expertise, and also in accelerating the search for patient data, the increase in the completeness of the information in facilitating the work, and ultimately in improving the quality of care [60].

Another project using mobile technologies for decision support in Africa is taking place in Uganda: the Uganda Health Information Network [59, 61]. The project involves the digitization of local and international guidelines adapted to the context. Then, these data are integrated into Personal Digital Assistants (PDAs) and distributed to health professionals for decision support.

For all these projects, financial viability and durability problems have been uncovered.

\section{Consumer Decision Support Systems}

Research has highlighted the willingness of patients to be involved in decision making about their health and healthcare [62] and the need for them to access their medical records in order to increase their participation in the process of their care for better outcomes [63]. The decision support in this context, therefore, aims to assist the patients to make appropriate choices regarding their own health care [64]. Given the poverty of the majority of the populations and insufficient health services in Africa, the trend is the development of systems that will enable patients to maximize their ability for self reliance and avoid long journeys which often entails unnecessary costs.

In this context, we have found in the literature a decision support system developed in rural areas of South Africa [65]. Based on primary care issued for common diseases such as tuberculosis, hypertension, bronchitis, the computerized decision support system was developed. This application allows the collect of data about the symptoms provided by the patient in a structured way. It analyzes them and provides to patient, information on ways to access the health care services. Rather than a diagnostic tool, it is actually an advisory system where the main recommendation issued is whether or not to consult a health care professional [65].

Also in South Africa, a system of sending reminders via SMS through mobile phone for well-defined periods, was used as an alternative to the "Directly observed therapy system" for patients' participation in the treatment of tuberculosis [66].

However, it is important to note that the usefulness of such systems is most obvious when patients are faced with complex decisions $[67,68]$. At the current stage, these systems only target the most educated portion of the population [66].

\section{Discussion}

Numerous studies demonstrate the potential of decision support tools for improving health care systems. Although the interest in electronic health care systems in African countries is recent, different types of tools developed for improving medical decisions in the rest of world are being used. These systems, as well as telemedicine tools are relevant solutions to some of the challenges facing the African health care plans.

However, many specific problems still limit their widespread use. Among them: the relative lack of organization of the systems, inadequate infrastructure, shortage and the disparity of health professionals, lack of technical skills, language barriers, and the still high proportion of illiterate populations. These tools can be implemented successfully only by improving the basic infrastructure (supply of electricity and connectivity to the Internet) but also through training of all stakeholders, clinicians, managers, health care system decision makers, and, eventually, patients and citizens. Nevertheless, the wide adoption and use in the African population of mobile technologies like cell phones, and long-distance, wireless connectivity with Wimax have a great potential for the diffusion and access to tools for decision support. These technologies have the advantage of being cheaper than satellite, consume little energy, and are relatively easy to deploy.

Thus, it is important to drive good evaluation studies in Africa on the decision support systems. Taking into account the specific problems of Africa, these assessments are intended to better adapt existing solutions for enhanced use and sustainability.

\section{References}

1. Miller RA, Masarie FE. The demise of the "Greek Oracle" model for medical diagnostic systems. Methods Inf Med 1990;29:1-2.

2. Miller RA. Medical diagnostic decision support systems - past, present, and future. J Am Med In- 
form Assoc 1994;1:8-27.

3. Geissbuhler A, Miller RA. Computer-Assisted Clinical Decision Support. In: Chapman G, Sonnenberg F, editors. Decision Research in Health and Medicine. Cambridge UK: Cambridge University Press; 2000.

4. Dick RS, Steen EB. The Computer-based Patient Record. An Essential Technology for Health Care. Washington DC: National Academy Press; 1991.

5. Gardner RM, Hawley WL, East TD, Oniki A, Young HF. Real Time Data Acquisition: Experience With the Medical Information Bus (MIB). Proceedings Symposium on Computer Applications in Medical Care 1992;813-7.

6. Haynes RB, McKibbon KA, Walker CJ, Ryan N, Fitzgerald D, Ramsden MF. Online access to MEDLINE in clinical settings. A study of use and usefulness. Ann Intern Med 1990;112:78-84.

7. McDonald CJ, Tierney WM, Overhage JM, Martin DK, Wilson GA. The Regenstrief Medical Record System: 20 years of experience in hospitals, clinics, and neighborhood health centers. MD Comput 1992;9:206-17.

8. Tierney WM, Miller ME, Overhage JM, McDonald CJ. Physician inpatient order writing on microcomputer workstations. Effects on resource utilization. JAMA 1993;269:379-83.

9. Cimino JJ, Socratous SA, Clayton P. Internet as clinical information system: application development using the World Wide Web. J Am Med Inform Assoc 1995;2:273-84

10. Geissbuhler A, Miller RA. A new approach to the implementation of direct care-provider order entry. Proc AMIA Annu Fall Symp 1996;689-93.

11. Evans RS, Pestotnik SL, Classen DC, Clemmer TP, Weaver LK, Orme JF Jr, et al. A computerassisted management program for antibiotics and other antiinfective agents. N Engl J Med 1998:338:232-8.

12. Ball MJ, Collen MF. Aspects of the Computer-based Patient Record. New York:Springer Verlag; 1992.

13. Coiera E, Lau AYS, Tsafnat G, Sintchenko V, Magrabi F. The Changing Nature of Clinical Decision Support Systems: a Focus on Consumers, Genomics, Public Health and Decision Safety. Yearb Med Inform 2009;84-95.

14. Tan JKH. An introduction to health decision support systems: definition, evolution, framework. In: Tan JKH, Sheps S, editors. Health Decision Support Systems; 1998. p. 3-32.

15. Lippeveld T, Sauerborn R, Bodart C. Design and Implementation of Health Information Systems. Geneva; WHO Press; 2000.

16. Shaw V. Health information system reform in South Africa: developing an essential data set. Bull World Health Organ 2005;83:632-6.

17. Rommelmann V, Setel PW, Hemed Y, Angeles G, Mponezya $\mathrm{H}$, Whiting D, et al. Cost and results of information systems for health and poverty indicators in the United Republic of Tanzania. Bull World Health Organ 2005;83:569-77.

18. Geissbuhler A, Bagayoko CO, Ly O. The RAFT network: 5 years of distance continuing medical education and tele-consultations over the Internet in French-speaking Africa. Int J Med Inform 2007;76:351-6.
19. Odhiambo-Otieno GW, Odero WW. Evaluation criteria for the district health management information systems: lessons from the Ministry of Health, Kenya. Afr Health Sci 2005;5:59-64.

20. Odhiambo-Otieno GW. Evaluation of existing district health management information systems: a case study of the district health systems in Kenya. Int J Med Inform 2005;74:733-44.

21. Williamson L, Stoops N, Heywood A. Developing a District Health Information System in South Africa: a social process or technical solution? Stud Health Technol Inform 2001;84:773-7.

22. Tessier SF. [The role of a health information system as an aid in making regional public health decisions. Experience in Botswana (Southern Africa)]. Med Trop (Mars) 1989;49:163-9.

23. Hanmer L. Criteria for the evaluation of district health information systems. Int J Med Inform 1999;56:161-8.

24. Lungo JH. The reliability and usability of district health information software: case studies from Tanzania. Tanzan J Health Res 2008;10:39-45.

25. Garrib A, Stoops N, McKenzie A, Dlamini L, Govender T, Rohde J, et al. An evaluation of the District Health Information System in rural South Africa. S Afr Med J 2008;98:549-52.

26. Mate KS, Bennett B, Mphatswe W, Barker P, Rollins N. Challenges for routine health system data management in a large public programme to prevent mother-to-child HIV transmission in South Africa. PLoS One 2009;4:e5483.

27. Mghamba JM, Mboera LEG, Krekamoo, Senkoro KP, Rumisha SF, Shayo E et al. Challenges of implementing integrated disease surveillance and response strategy using the current health management information system in Tanzania. Tanzania Health Research Bulletin 2004;6:57-63.

28. Makombe SD, Hochgesang M, Jahn A, Tweya H, Hedt B, Chuka S, et al. Assessing the quality of data aggregated by antiretroviral treatment clinics in Malawi. Bull World Health Organ 2008:86:310-4.

29. Otwombe KN, Wanyungu J, Nduku K, Taegtmeyer $\mathrm{M}$. Improving national data collection systems from voluntary counselling and testing centres in Kenya. Bull World Health Organ 2007:85:315-8.

30. Heywood AB, Campbell BC. Development of a primary health care information system in Ghana: lessons learned. Methods Inf Med 1997;36:63-8.

31. WHO. Framework and standards for country health information systems, 2nd Edition. Geneva; 2008.

32. Boerma T, Chopra M, Evans D. Health system performance in the Bulletin. Bull World Health Organ 2009;87:2.

33. WHO. Toolkit for Monitoring Health Systems Strengthening: Service Delivery. 2008.

34. Africa Health Infoway. http://www.who.int/ africahealthinfoway/en/, last accessed on April 2010.

35. Wolfe BA, Mamlin BW, Biondich PG, Fraser HS, Jazayeri D, Allen C, et al. The OpenMRS system: collaborating toward an open source EMR for developing countries. AMIA Annu Symp Proc 2006;1146

36. Hannan TJ, Rotich JK, Odero WW, Menya D, Esamai F, Einterz RM, et al. The Mosoriot medical record system: design and initial implementation of an outpatient electronic record system in rural Kenya. Int J Med Inform 2000;60:21-8
37. Rotich JK, Hannan TJ, Smith FE, Bii J, Odero $\mathrm{WW}, \mathrm{Vu} \mathrm{N}$, et al. Installing and implementing a computer-based patient record system in sub-Saharan Africa: the Mosoriot Medical Record System. J Am Med Inform Assoc 2003;10:295-303.

38. Siika AM, Rotich JK, Simiyu CJ, Kigotho EM, Smith FE, Sidle JE, et al. An electronic medical record system for ambulatory care of HIV-infected patients in Kenya. Int J Med Inform 2005;74:345-55.

39. Tierney WM, Rotich JK, Hannan TJ, Siika AM, Biondich PG, Mamlin BW, et al. The AMPATH medical record system: creating, implementing, and sustaining an electronic medical record system to support HIV/AIDS care in western Kenya. Stud Health Technol Inform 2007;129:372-6.

40. Douglas GP, Deula RA, Connor SE. The Lilongwe Central Hospital Patient Management Information System: a success in computer-based order entry where one might least expect it. AMIA Annu Symp Proc 2003;833

41. Allen C, Jazayeri D, Miranda J, Biondich PG, Mamlin BW, Wolfe BA, et al. Experience in implementing the OpenMRS medical record system to support HIV treatment in Rwanda. Stud Health Technol Inform 2007;129:382-6.

42. Milberg J. Adapting an HIV/AIDS clinical information system for use in Kampala. HELINA 2003. Johannesburg: HELINA; 2003. p. 44-5.

43. Mamlin BW, Biondich PG, Wolfe BA, Fraser H Jazayeri D, Allen C, et al. Cooking up an open source EMR for developing countries: OpenMRS a recipe for successful collaboration. AMIA Annu Symp Proc 2006;529-33.

44. Were MC, Mamlin BW, Tierney WM, Wolfe B, Biondich PG. Concept dictionary creation and maintenance under resource constraints: lessons from the AMPATH Medical Record System. AMIA Annu Symp Proc 2007;791-5.

45. Williams F, Boren SA. The role of the electronic medical record (EMR) in care delivery development in developing countries: a systematic review. Inform Prim Care 2008;16:139-45.

46. Safran C, Rind DM, Davis RB, Ives D, Sands DZ, Currier J, et al. Guidelines for management of HIV infection with computer-based patient's record. Lancet 1995;346:341-6.

47. Bates DW, Cohen M, Leape LL, Overhage JM, Shabot MM, Sheridan T. Reducing the frequency of errors in medicine using information technology. J Am Med Inform Assoc 2001;8:299-308.

48. Fraser HS, Biondich P, Moodley D, Choi S, Mamlin BW, Szolovits P. Implementing electronic medical record systems in developing countries. Inform Prim Care 2005;13:83-95.

49. Tierney WM, McDonald CJ, Martin DK, Rogers MP. Computerized display of past test results. Effect on outpatient testing. Ann Intern Med 1987;107:569-74

50. Whiting-O'Keefe QE, Simborg DW, Epstein WV, Warger A. A computerized summary medical record system can provide more information than the standard medical record. JAMA 1985;254:1185-92.

51. Shea S, DuMouchel W, Bahamonde L. A metaanalysis of 16 randomized controlled trials to evaluate computer-based clinical reminder systems for preventive care in the ambulatory setting. J Am Med Inform Assoc 1996;3:399-409. 
52. Seebregts CJ, Mamlin BW, Biondich PG, Fraser HS, Wolfe BA, Jazayeri D, et al. The OpenMRS Implementers Network. Int J Med Inform 2009;78:711-20.

53. McDonald CJ. The barriers to electronic medical record systems and how to overcome them. J Am Med Inform Assoc 1997;4:213-21

54. Brauchli K, O'mahony D, Banach L, Oberholzer M. iPath - a Telemedicine Platform to Support Health Providers in Low Resource Settings. Stud Health Technol Inform 2005;114:11-7.

55. Brauchli K, Oberli H, Hurwitz N, Kunze KD, Haroske G, Jundt G, et al. Diagnostic telepathology: long-term experience of a single institution. Virchows Arch 2004;444:403-9.

56. Kaddu S, Kovarik C, Gabler G, Soyer HP. Teledermatology in developing countries. In: Wootton R, Patil NG, Scott RE, Ho K, editors. Telehealth in developing world. London; 2009.

57. O'Mahony D, Banach L, Mahapa DH, Lancaster $\mathrm{EW}$, van der Linde GD, Williams BH, et al. Teledermatology in a rural family practice. SA Fam Pract 2002;25:4-8.

58. Soyer HP, Hofmann-Wellenhof R, Massone C, Gabler G, Dong H, Ozdemir F, et al. telederm.org: freely available online consultations in dermatol- ogy. PLoS Med 2005;2:e87.

59. Iluyemi A. Community-based health workers in developing countries and the role of m-health. In: Wootton R, Patil NG, Scott RE, Ho K, editors. Telehealth in developing world. London; 2009.

60. Merrell RC, Merriam N, Doarn C. Information support for the ambulant health worker. Telemed J EHealth 2004;10:432-6.

61. IDRC. Uganda Health Information Network (UHIN). www.idrc.ca/ev_en.php?ID=86353_201\&ID2= DO_TOPIC, last accessed on April 2010.

62. Deber RB, Kraetschmer N, Irvine J. What role do patients wish to play in treatment decision making? Arch Intern Med 1996;156:1414-20.

63. Berner ES. Clinical decision support system: Theory and pratice. New York: Springer-Verlag; 1999.

64. O'Connor AM, Stacey D, Rovner D, Barry M, Col $\mathrm{NF}$, Eden KB, et al. Decision aids for people facing health treatment or screening decisions. Cochrane Database Syst Rev 2001;CD001431.

65. Horner V, Hanmer LA, Mbananga ND. A consumer decision support system for common health ailments in South Africa. Stud Health TechnolInform 2006;122:1027.

66. Hüsler J. Evaluation of the On Cue Compliance Service Pilot. Testing the use of SMS reminders in the treatment of Tuberculosis in Cape Town, South Africa. Technology Associate, bridges.org. City of Cape Town Health Directorate and the InternationalDevelopment Research Council (IDRC); 2005.

67. O'connor A. Using patient decision aids to promote evidence-based decision making. ACP J Club 2001;135:A11-2.

68. O'connor AM, Fiset V, Degrasse C, Graham ID, Evans W, Stacey D, et al. Decision aids for patients considering options affecting cancer outcomes: evidence of efficacy and policy implications. J Nat Cancer Inst Monogr 1999;25:67-80.

\section{Correspondence to: \\ Dr. Georges Bediang}

Division of Medical Informatics

University Hospitals of Geneva

Rue Gobrielle-Perret-Gentil 4

1211 Geneva 14

Switzerland

E-mail: georges.bediang@sim.hcuge.ch 